\title{
Interview
}

\section{In conversation with Maurice Silverman}

\author{
Hugh Freeman interviewed Dr Silverman recently
}

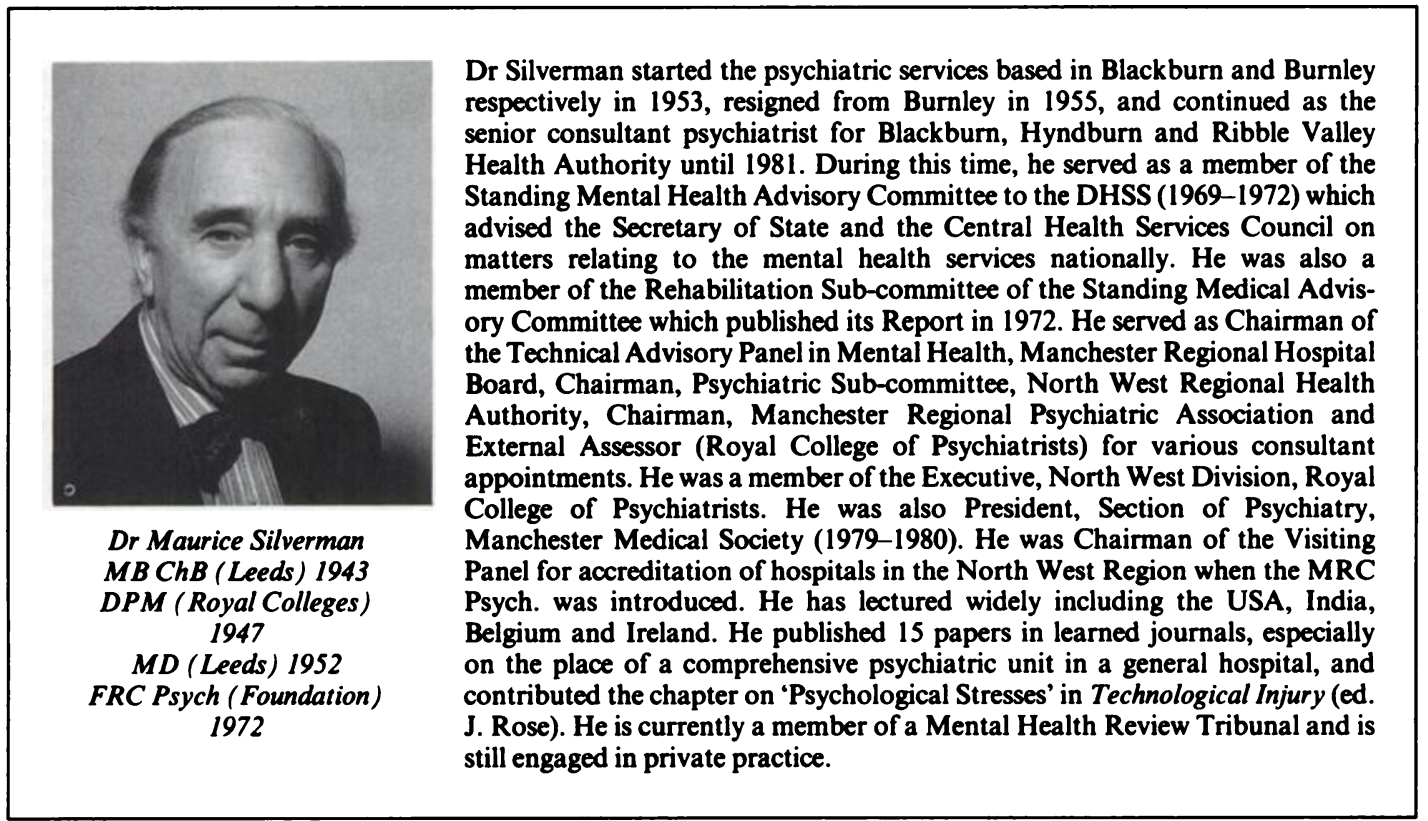

Could you tell me first about your early career in medicine and the first jobs that you did?

After qualifying, as a matter of fact, I did two house jobs, both in general medicine. Like many students, I had developed an interest in psychology, so when it came to my third job, I thought I would see what psychiatry had to offer - this was pre-Health Service. It was actually at Scalebor Park - a private hospital with about 200 beds in those days, now associated with the University of Leeds. My chief, Jim Valentine, had been at Johns Hopkins with Adolf Meyer; he was young, stimulated my interest in the subject and $I$ have remained in psychiatry ever since. I was there for two years from November, 1944, and then I was called up into the Army. As I had already got the first part of my DPM, I was immediately posted as a psychiatrist.

The first posting I had was to Northfield in Birmingham which was the Neurosis Centre in the
Army for patients evacuated as psychiatric casualties from all over the world. One of the medical staff would go to Southampton, stay there for the night, and escort the casualties in a special train to Northfield. When these patients arrived, each member of the medical staff would do brief assessments with about ten of them. Now, as you may know, in the Army one couldn't make any diagnosis; there was an official list and one had to choose from the diagnoses in that list. Rather to my amazement, when I asked the first patient what he complained of, he looked me straight in the eye with a deadpan expression and said, "I'm, a psychopathic personality with abnormal sexual trends, sir". As time went on, I noticed that all the patients were simply quoting the official diagnoses from this list.

After about six weeks, my turn came to go to Southampton to pick up the casualties. When I got on the ship, every patient there, from every branch of medicine, had his diagnosis pinned on his lapel. I 
enquired about this and was told that originally it was to ensure that someone with, say, a fractured femur, wouldn't be manhandled, but as often happens in the Army, this had been taken out of context, and everyone had his diagnosis spotlighted. Of course, if you've been travelling about a third of the way around the world with "Psychopathic personality with abnormal sexual trends" pinned on your uniform, it's understandable why this was given as a response when you arrived at Northfield. Apparently, no-one had ever discovered this before!

The Northfield Experiment is quite well known historically, and a number of very well known names were associated with it. What was your experience there?

In general terms, it was extremely disappointing. I have read the book by Foulkes and Anthony, but I found an enormous gulf between the way the book interpreted Northfield and the way I found it. I saw awfully little real therapy being done. The one exception to that was Martin James, a well-known psychoanalyst who had, I believe, been analysed by Anna Freud. I took the opportunity of sitting in with him and his group regularly for the whole of the 12 months that I was there. This I found very instructive, but Martin James refused to give ECT to any patient, on principle, so that if anyone in his ward manifestly required it, all sorts of subterfuges had to be adopted to move the patient off his ward.

In my time at Northfield, there was a very heterogeneous collection of patients there, many of whom in the lingo of those days, would have been described as spivs. Doing my ward round one day, I asked one patient "How are you this morning?" and the reply I got was "Would you like any nylons, doc?". I was in charge for a time of the officers' wing, where we had quite a number of patients who'd joined the Army as regulars. They were jibbing very much about peacetime soldiering and one of them, when we discharged him, went to live on an island in the Outer Hebrides. He maintained contact with other patients, and a whole succession of ex-officers joined him there. I often wonder what happened to this little colony.

There was also one closed ward in Northfield, but admission to it had nothing to do with the patient's clinical condition. It was a technical point. If the patient was serving a sentence before he came into Northfield, he was automatically admitted to this closed ward, where he continued to serve his sentence. There was one patient who had been given a nine-month sentence, and he had the temerity to appeal against this, so that while the appeal was pending, he had to remain in the closed ward. As a result of this, he was in this ward for 18 months, whereas if he had served his sentence, he would have only served nine. To add insult to injury, he then won his appeal!

\section{From Northfield, where did you go next?}

I was posted to Singapore. There were two Army psychiatrists in Singapore, of whom I was one, and we dealt with virtually all the psychiatric casualties who came through from the Far East to be evacuated to the UK, in addition to treating local personnel. I was stationed at the British Military Hospital in Alexandria. This was where the Japanese came in, crossing the grounds of the hospital while the guns faced in the opposite direction. I also served on a Regular Commissions Board which was choosing officers for regular commissions in the Army. The standards were extraordinarily high, one of the reasons being that there was then an enormous number of candidates whose only training had been in the Army, so this offered the opportunity for a career in the one subject they knew.

The first week I was in Singapore, I got a 'phone call, saying that I was expected to go to Changi Prison on the last Friday afternoon in every month. On the first Friday, a couple of soldiers arrived in a jeep to pick me up, and while we were on the way, I asked them why I was going there. They said they hadn't a clue, and that their job was just to take me. Though the Army documentation as a whole was extremely good, I just couldn't find anything referring to this particular venture. This was a Category $C$ prison - one for long-term prisoners - most of whom had done something pretty ghastly. I was sat at a trestle table in the open air, a sergeant always gave me a very hot cup of tea, and I would ask a few casual questions of the incoming prisoners - usually about half-a-dozen of them. I did this for 12 months, and to this day, I'm not absolutely clear why I was there.

While in Singapore, I came to the firm conclusion that the patients with so-called 'hysterical amnesia' knew exactly what they were doing. Unlike civilian practice, one saw a fair number of men with this form of clinical presentation, some of whom had gone absent without leave. Certainly with pentothal, which we used in those days, but even sometimes without, it was quite easy to fill in the gaps in memory.

I wrote the first paper which I ever published when I was there. I was very friendly with Gordon Ransome, a neurologist trained in London, who was Professor of Medicine at the Singapore teaching hospital. I wrote up a patient who developed a paranoid reaction during the phase of recovery from a subarachnoid haemorrhage. This is quoted in Lishman's book on Organic Psychiatry.

\section{What happened when you left the Army?}

I returned to the UK in May, 1949 and took up the post of registrar at St Clement's Hospital in the East End of London. This had been one of the old LCC observation wards, and it had had a direct hit during 
the War. At that time, it was a unit run jointly between The London Hospital and Claybury. The two visiting consultants were John Stuart Harris from Claybury who at one time, had been the Deputy Director of the Maudsley, and the other was Pat Tooley from the London, who died fairly recently. This was the time when the NHS was in its early days. In this old observation block, we gradually introduced a fair amount of active treatment, and it eventually became part of The London Hospital. During that time, I developed a certain interest in hypnosis, which I have always felt is a very neglected field. I went to the courses run by the British Society of Medical \& Dental Hypnosis, and found them very useful. I believe that in many tension states, irritable bowel syndrome, psychogenic dermatological states, and so on, there is very great scope for hypnosis. It means that you are not using medication and, in competent hands, the results are extremely good. Ever since then, I always took the opportunity of teaching junior doctors the basic concepts of hypnosis.

\section{Your first experience of a large mental hospital was at Claybury?}

That's right. I went there from St Clement's, and also took on an out-patient clinic at the North Middlesex Hospital and Chase Farm Hospital, Middlesex. This was my first contact with the large number of long-stay patients that one saw in the large mental hospital. Although I was well aware of the history of the build-up of the long-stay population, from the very beginning, I couldn't help but question this and ask whether it meant one had to continue in the same way. I felt I was the one who was rocking the boat, particularly in our morning meetings of the medical staff. I began to question the whole set-up, and wasn't exactly very popular for doing this. It was to some extent with all this in mind that the MD thesis I did ultimately came about on psychological and social aspects of psychiatric disorders in the aged.

Your first major research was done on the elderly; would you like to say something about your findings then or your subsequent work in that area.

For my MD thesis, I took four elderly groups: one were normal controls, the second were residents in the 'eventide' homes in London, the third were patients in a geriatric hospital, and the fourth were those in psychiatric beds of a large mental hospital. I aimed to measure the degree of social integration of these individuals prior to them coming into the various facilities, and it was noticeable-contrary to what one might have expected - that the degree of their social integration prior to admission was just as good as in the normal controls. Some years later, I extended this research over a longer period of time, taking a much greater number of patients, and this finding on social integration was confirmed. Another point confirmed was the effect of prolonged inactivity following the cessation of regular work. Comparing the controls and the patients admitted into psychiatric beds, I measured the interval of time between individuals ceasing regular work and the development of frank psychiatric ill-health, and controlled the observations by ascertaining the interval between ceasing regular work and the date of the interview in the normal control population. This showed that the interval was significantly greater in the case of the patients than for the controls, which suggested prolonged inactivity following the cessation of regular work was conducive to psychiatric ill-health.

\section{After you were at Claybury for about two-and-a-half years, what happened next?}

I applied for two consultant posts at the same time - at Horton and at Blackburn. I got the one at Horton, and it was the not uncommon story of the "wrong" job coming up first. Though I'd accepted the Horton post, I consulted my chief, John Stuart Harris, and he said I should go ahead and do whatever I wished. I was then appointed to Blackburn. At that time, there was a policy in the Manchester Region to establish psychiatric units in district general hospitals, and I felt that this was the future. The idea attracted me and gave me the opportunity to put into practice all sorts of ideas that I'd had in my training. Believe it or not, I was actually appointed originally to Blackburn, to a similar unit in Burnley, and for a few sessions a week to Whittingham, a large mental hospital. I suppose this was the stage in the NHS when the region was just getting things off the ground in psychiatry, and one had to start at some point. Ultimately, I resigned from Burnley and Whittingham and simply kept my appointment at Blackburn.

I've always been something of a pragmatist, as I suppose most clinicians are, so that I can't honestly say that I started with any detailed plan in mind for what I intended to do. I just pressed ahead and these old observation wards were gradually converted into a fully-fledged psychiatric department. By 1959, the whole unit had been converted so radically that what was virtually a new unit was opened. This consisted of an acute in-patient section, an observation section for patients with behaviour problems and conduct disorder, and a long-stay section. By that time, we had already started a therapeutic social club, we were catering for day-patients, we had an Alcoholics Anonymous group meeting in the unit, and a new clinical psychology department. In September 1961, I published a review of the in-patient case-load in 
the British Medical Journal which covered a period of 12 months. I didn't feel I was doing anything special-just reviewing what was happening in this unit-but the publication of this paper produced something of a furore. Amongst other things, I was bombarded with professional visitors, who came from as far afield as Chile and Australia and within a matter of months, we had had in fact 26 such visits. People from the Ministry of Health came and visited us, and had long sessions with me. It was they who initiated what they saw as a 12-month study to see how the whole thing was functioning. I was invited to give lectures all over the place about our set-up. These included the BMA Psychological Medicine Group, a trip to Ireland, and an invitation from the American Psychiatric Association. I went to New York State Psychiatric Institute, Mount Sinai Hospital, New York, the National Institute of Mental Health and St Elizabeth's Hospital in Washington.

Could you summarise the difference between the kind of psychiatry you were practising at the Blackburn Unit and what your experience had been of the large mental hospital at Claybury?

I think the basic difference is that in the DGH unit, as a psychiatrist, you have a very much more intimate relationship with other personnel and with the surrounding community. Under 'other personnel', I'm including other consultants in every specialty, the GPs in the area, and community social workers. Beyond a certain point, though, it's one of those almost intangible things which is very difficult to define, but one is very conscious of when working in this kind of set-up. For example, instead of formal ward rounds, the mental welfare officers, psychiatric social workers, and other extramural staff came to medical case conferences, and if a particular patient was due for discharge, arrangements were made there and then for responsibility to be taken on by a particular social worker. Likewise, every Monday afternoon, I used to hold another case conference with the social workers, mental welfare officers, disablement resettlement officer, occupational therapist, clinical psychologist, and industrial workshop manager. When a patient had been discharged, a copy of the discharge report was put in a file, which I used to bring along to this conference. In this way, it was possible to ask all the various personnel concerned how these respective patients were doing, and what their problems were.

The effectiveness of after-care arrangements was monitored all the time. (I published a paper on all this in the British Medical Journal in July 1971.) It's one of many examples one could give of the kind of thing that happens in a general hospital unit which, in my experience, had no counterpart in mental hospitals. I believe that a psychiatrist in a DGH unit needs the ability to combine clinical skills with what I can only call management skills: to be able to assess priorities very clearly, to produce a kind of hierarchy of what needs to be done, and to keep in mind a plan as to where one is going. For example, one of many things I introduced was pre-admission screening. Even if a GP referred a patient in the dead of night, the duty doctor would see the patient and he alone would make the decision as to whether the patient should be admitted or not. Otherwise, there is a whole host of people with social problems - the loner, the chronic unstable drifter, the lonely elderly person - whose problems require tackling, but who are by no means necessarily candidates for the formal psychiatric service and who will take up beds and other scarce resources. At one point, through a mild feeling of guilt, I thought I'd call off pre-admission screening, and see how things went without this. This went on for a period of about six weeks, and it confirmed my worse suspicions, so we instituted it again.

Was there anything about the character of Blackburn and of the people there which perhaps affected the style of what you were doing, and which might have been different in many other parts of the country?

$\boldsymbol{P}$ don't know whether this necessarily applies to Blackburn as such, but I'd readily agree that there is a difference between the smaller town and the larger city. This is for fairly obvious reasons; the smaller town is more compact and more containable, and you are likely to know most of the relevant people who are involved in managing any particular problem. In a much larger city, things are more diffuse, detached, and more remote.

After your first paper in the BMJ, which created so much interest, I think you then did another one, reviewing the work of the unit.

Yes. In April, 1968 I published a paper in the British Journal of Psychiatry which was really an extension of the findings that had appeared in the BMJ, but the period was extended to four years. The criticism has often been made that a unit of the kind I was concerned with may function quite happily in its early days, but that sooner or later, it would become hopelessly blocked up. So I reviewed the admissions and discharges over that period, and I was extremely pleased to find that these confirmed the findings of the original 12-month review. The department was not being blocked by long-stay patients and, in fact, in all sorts of ways it was functioning better than at the time of the previous review. The administrative problems had actually become a good deal less. However, one of the outstanding difficulties is that of coping with patients who have a severe conduct disorder or behavioural problem in an era of no 
locked wards, especially taking into account the difficulty of funding adequate nursing staff. If you haven't got a closed ward for this type of patient, then you must, at the very least, have a high ratio of nursing staff to look after them. Apart from anything else, this problem places the medical staff in an extremely vulnerable situation.

Another aspect of the DGH unit is the relationship with the geriatric department. I believe that unless there are substantial behaviour or management problems, the geriatric department should take all the chronic sick patients who need long-term care from all the specialities in the district. This, you may recall, was part of the plan of Thomas McKeown. We were very fortunate to have a very harmonious relationship with the geriatric department. Also, when I was in full harness, I did many domiciliary visits, but I have the impression that this aspect of the service has diminished these days. If that is true, I think it will make serious inroads into the adequate functioning of a district unit.

Did you feel at this time that you were being a pioneer in developing a new model of psychiatric service?

I think the only honest reply to that would be 'yes'. There were only a handful of us doing anything like this, and one felt very much a kind of lone ranger, particularly because the majority of psychiatrists, who were not running this kind of unit, tended to some extent to attack the concept. This might seem strange today, but they felt that the large mental hospital had facilities to offer that could never be replaced in a DGH unit. They would have been thinking of the occupational facilities, for instance, and I well remember some colleagues reacting with disbelief when I told them that some of our out-patients worked in the laundry of the general hospital, which showed that this sort of thing could be done there. But now, nearly everyone seems to be travelling along the road which I and some others did indeed pioneer.

In 1969, I think you were invited to serve on the Standing Mental Health Advisory Committee.

That's right. I ought to explain that the Standing Mental Health Advisory Committee advised the Central Health Services Council, and the Secretary of State, on the running of the mental health service at a national level. I emphasise the word 'national' because part of our remit was that no local problems could be brought up. It was chaired by Sir William Trethowan, who I might add did a superb job. It was my first real introduction to consensus decisionmaking, and I must admit that initially I found it a bit difficult to fit in with. We were making pretty important decisions and recommendations at a national level, and I felt that one should take a majority vote on these things. But this, I'm afraid, was never done; there had to be a consensus. I was asked by the Committee to write a discussion paper on provisions for the antisocial psychopath. I wrote to all the obvious people concerned, getting their opinions, but these were so diverse - and it was felt that in a fundamental sense, so little was known about the problem - that the main emphasis at that stage would have to be on research. It was, of course, disappointing from the practical point of view.

During my time on this Committee, I was seconded to the Standing Medical Advisory Committee to serve on one of their sub-committees - the Rehabilitation Sub-Committee. This was chaired by Sir Ronald Tunbridge, who as a matter of fact had been one of the examiners of my MD thesis, and our report was published in 1972. There were 15 of us on this Sub-Committee. Douglas Bennett and I were the only psychiatrists. I think we psychiatrists kept our end up very well, though this wasn't very easy because the whole emphasis initially was on physical aspects of rehabilitation. I felt very much out on a limb at the beginning. As the completion of this report was dragging on, Sir Ronald got to the point where he invited us all to Littlehampton for a weekend, insisting that we cancel any other commitments. We all did this. There was $100 \%$ turnout and the thing that intrigued me more than anything was the marvellous competence of the two secretaries from the Department who put together this report from our rather higgeldy-piggeldy deliberations. Douglas Bennett and I produced a chapter on the psychiatric aspects of rehabilitation, and I am very happy to say we managed, with a great deal of effort, to make an impact on the report as a whole. When we finished a new rehabilitation unit as part of our department in Queen's Park Hospital, Blackburn, I arranged for Sir Ronald Tunbridge to come along and open the Department. We modelled it, of course, on the lines recommended in the report and, as had been envisaged, appointed a consultant with a special interest in psychiatric rehabilitation.

\section{You then wrote several papers about the work of general hospital units.}

Yes. One was an evaluation of the day-patient activities, which confirmed my impression that those day-patients who attended satisfactorily had fewer in-patient admissions, compared with other daypatients. The other paper was on community attitudes to day care. I felt this was very important because one was, in effect, pushing more of the burden on to the community. One of the things that came out of it was that, of the relatives in the community whom we interviewed, $50 \%$ thought that the gravity of caring for those day-patients had been 
reduced from their point of view. It didn't reduce the need for day care in any way, but there was less pressure on the relatives or other individuals caring for these day-patients. There was another publication in the BMJ (referred to already) on after-care. This was a three-year review, and I found that of the patients referred for after-care, $50 \%$ had not been readmitted. Also, only $6.3 \%$ of those below retirement age had been unemployed for $75 \%$ or more of their working time in the follow-up period. In other words, there were really very few who had been referred for aftercare who were in fact unemployed. So it seemed that the service was working and that, in this respect, we were achieving what we had set out to do.

\section{What has been your experience of Mental Health Review Tribunals?}

On the whole, I think they do a good job. I know that there is a lot of criticism of them and there is one aspect that I would like to comment on. It seems to me that the remit of the Tribunal is much too narrow, which makes the whole procedure excessively rigid; basically it is whether the patient should be discharged or not discharged at a particular point in time. This doesn't cover the very large grey area that one comes across with many patients, and this has become more difficult since the replacement of the 1959 Mental Health Act. There has also been the Hallstrom case, which concluded that 'detained' means exclusively 'detained as an in-patient in hospital' and this again limits the scope of the
Tribunal very severely. I don't feel that the Tribunal is set up in such a way that it can really function at its best for many patients who are brought before it.

Any general conclusions or lessons about the state of psychiatry?

So far as the district general hospital psychiatric unit is concerned, I feel very strongly that psychiatry is an integral part of medicine, which in its turn is part of the biological sciences. For that reason, I think it is part of the duty of the consultant psychiatrist to mix very actively with the other non-psychiatric consultants in the district. This will increase the demands for liaison psychiatry, which means adding to one's work. When I was visiting Mount Sinai Hospital, New York, amazing as it may seem, I found that they had a psychiatrist attached to every single ward in the hospital, which shows what can be done.

Another need is to delimit the scope of the formal psychiatric services. In July, 1952 Desmond Curran wrote a paper called 'Psychiatry Limited', which I thought was superb. In it, he said, "The sensible view is surely that many individuals present social rather than medical problems". Apart from any other consideration, if one accepts responsibility for a whole host of social problems which are not associated with any formal psychiatric abnormality, one helps to distort the information available to local authorities who cater for those in need of social care. In the long term, that is doing a disservice to the community as a whole. 